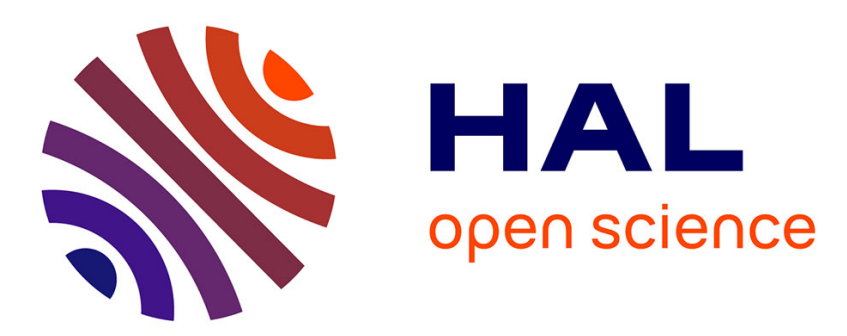

\title{
Optical properties of size selected neutral Ag clusters: electronic shell structures and the surface plasmon resonance
}

Chongqi Yu, Romain Schira, Harald Brune, Bernd von Isserdoff, Franck Rabilloud, W. Harbich

\section{To cite this version:}

Chongqi Yu, Romain Schira, Harald Brune, Bernd von Isserdoff, Franck Rabilloud, et al.. Optical properties of size selected neutral Ag clusters: electronic shell structures and the surface plasmon resonance. Nanoscale, 2018, 10 (44), pp.20821-20827. 10.1039/C8NR04861D . hal-03031060

\section{HAL Id: hal-03031060 https://hal.science/hal-03031060}

Submitted on 30 Nov 2020

HAL is a multi-disciplinary open access archive for the deposit and dissemination of scientific research documents, whether they are published or not. The documents may come from teaching and research institutions in France or abroad, or from public or private research centers.
L'archive ouverte pluridisciplinaire HAL, est destinée au dépôt et à la diffusion de documents scientifiques de niveau recherche, publiés ou non, émanant des établissements d'enseignement et de recherche français ou étrangers, des laboratoires publics ou privés. 


\title{
Journal Name
}

\section{ARTICLE TYPE}

Cite this: DOI: $10.1039 / x x x x x x x x x x$

\section{Optical properties of size selected neutral Ag clus- ters: electronic shell stuctures and the surface plas- mon resonance ${ }^{\dagger}$}

\author{
Chongqi Yu, ${ }^{* a}$ Romain Schira, ${ }^{b \ddagger}$ Harald Brune, ${ }^{a \neq}$ Bernd von Issendorff, ${ }^{c}$ Franck \\ Rabilloud, ${ }^{\ddagger \ddagger}$ and Wolfgang Harbich ${ }^{a}$
}

Received Date

Accepted Date

DOI: 10.1039/xxxxxxxxxx

www.rsc.org/journalname

\begin{abstract}
We present optical absorption spectra from the ultraviolet to the visible for size selected neutral $\mathrm{Ag}_{n}$ clusters $(n=5-120)$ embedded in solid $\mathrm{Ne}$. We compare the spectra to time-dependent density functional calculations (TDDFT) that address the influence of the Ne matrix. With increasing size, several highly correlated electron excitations gradually develop into a single surface plasmon. Its energy is situated between 3.9 and $4.1 \mathrm{eV}$ and varies with size according to the spherical electronic shell model. The plasmon energy is highest for clusters with atom numbers fully filling states with the lowest radial quantum number (e.g. $1 s, 1 p, 1 d \ldots)$. TDDFT calculations for clusters with several candidate geometrical structures embedded in Ne show excellent agreement with the experimental data, demonstrating that the absorption bands depend only weakly on the exact structure of the cluster
\end{abstract}

\section{Introduction}

Small noble metal clusters and nano-particles have particular optical properties related to the energetically localized surface plasmon which determines the optical absorption spectrum in the UVvisible wavelength range. These properties make them interesting for bio-labelling, nanophotonics, light energy harvesting, sensing, electronics, and catalysis 1.5 . The investigation and fundamental understanding of the optical properties of these small metal clusters are key for the development of applications. The optical properties of very large metal particles in the nanometer size range can be characterized to a very good approximation in the framework of classical electromagnetic theory using the dielectric function of the bulk material 2 . On the other hand, very small metal clusters containing less than 10 atoms exhibit molecular optical properties and therefore have to be treated with detailed quantum chemical methods like TDDFT7 71 . In addition, these calculations have to take the cluster structure into account since for this size range it

\footnotetext{
a Institute of Physics, Ecole Polytechnique Fédérale de Lausanne (EPFL), CH-1015 Lausanne, Switzerland

${ }^{b}$ Université Claude Bernard Lyon 1, CNRS, Institut Lumière Matière, F-69622 Villeurbanne, France

${ }^{c}$ Université Fakultät für Physik, Universität Freiburg, Germany

$\dagger$ Electronic Supplementary Information (ESI) available: [details of any supplementary information available should be included here]. See DOI: 10.1039/b000000x/ $\ddagger$ Additional footnotes to the title and authors can be included e.g. 'Present address:' or 'These authors contributed equally to this work' as above using the symbols: $\ddagger, \S$, and 9 . Please place the appropriate symbol next to the author's name and include a $\backslash$ foot notetext entry in the the correct place in the list.
}

has a significant influence on the optical properties.

While these two size ranges have been extensively studied, data on the intermediate non-scalable $e^{12 \mid 13}$ size regime is scarce, mainly because this regime is experimentally and theoretically much more challenging. At the nanoscale, the well known surface plasmon resonances, classically understood as a collective response of valence electrons, are characterized by an absorption band whose shape depends on the symmetry of the particle 1415 . Its center wavelength and width changes as a function of $\operatorname{size}{ }^{6}$, smoothly for larger particles, more dramatically for the very small ones.

Silver clusters are particularly interesting since their $4 d$ and $5 s$ electrons are sufficiently far in energy to enable a fundamental understanding of their respective roles, at the same time, they are sufficiently close to enable mutual interactions. Specifically, the $4 d$ electrons quench the oscillator strengths by screening the $5 s$-electrons and get partially involved in excitations. A recent paper $\frac{16}{16}$ shows the center of the plasmon absorption (for small clusters the center of the several discrete absorption lines) as a function of cluster size. Large particles show a monotonous redshift of the plasmon energy with increasing cluster size, which is fairly well understood since their dielectric function is close to that of bulk. Very small particles (up to 39 atoms), which have been measured on mass selected neutral clusters, clearly do not follow the trend of a monotonous redshift for increasing size but show shell closing and multi peak absorption spectra ${ }^{17} 18$. The intermediate size regime ( $40-120$ atoms) is not covered by measurements on size selected neutral clusters and this is the gap we 
are filling with this paper.

We present optical absorption measurements on neutral, size selected silver clusters embedded in a solid neon matrix at $6 \mathrm{~K}$. These spectra are recorded on monodisperse cluster ensembles for sizes from 1 to 120 atoms and provide a unique way to investigate the evolution of the plasmon energy with size. TDDFT calculations are compared with the experimental results.

\section{Experimental and theoretical methods}

\subsection{Experiment}

The experimental setup couples a sputter gas aggregation cluster source ${ }^{19}$ to a newly designed cluster ion beam line which allows for single mass selection 20. Clusters are injected in a custom built conical octupole $\mathrm{e}^{21}$, guided by a radio-frequency coupled quadrupole, and mass-selected by a high-mass quadrupole (extranuclear). Cluster ions up to $16000 \mathrm{amu}$ can be selected with an electronically controllable mass resolution. The cluster cations are deposited with a kinetic energy of $10 \mathrm{eV}$, and coadsorbed with Neon forming the matrix, on a super polished aluminium mirror held at $6 \mathrm{~K}$. The cluster ions are neutralized after deposition by an electron cloud formed in front of the matrix. The excess energy from the neutralization process is coupled into the rare gas support avoiding fragmentation. The matrix has a thickness of $50 \mu \mathrm{m}$ and the ratio of clusters to rare gas atoms is typically $10^{-4}$ which ensures that mutual interactions between clusters can be neglected while still yielding sufficient signal.

The deposition time varies between 120 and 240 min, depending on the cluster size. Optical absorption measurements are performed in transmission through the $2 \mathrm{~mm}$ long matrix. The transmitted light is collected with an optical fiber of $400 \mu \mathrm{m}$ core diameter and analyzed by an optical spectrometer coupled to a liquid-nitrogen-cooled charge coupled device. Comparing the intensity of the light passing through a matrix containing clusters with a reference spectrum recorded for a pure neon matrix yields the absorption spectrum according to Beer's law. The optical setup covers the UV-visible wavelength range between $250 \mathrm{~nm}$ and $1 \mu \mathrm{m}$.

\subsection{Calculation method}

Very few theoretical studies have considered the effects of the rare-gas matrix on the optical response of metal clusters ${ }^{1120|22| 23}$. Here our simulations considered clusters both in gas phase and embedded in a Ne matrix. TDDFT calculations have been performed using range-separated hybrid density functionals, namely $\omega \mathrm{B} 97 \mathrm{x}^{24}$ for $\mathrm{Ag}_{20}, \mathrm{Ag}_{35}, \mathrm{Ag}_{58}$ and $\mathrm{Ag}_{92}$, and LC$\operatorname{M06L}(\mu=0.33)^{25 \mid 26}$ for $\mathrm{Ag}_{55}$. A relativistic effective core potential (RECP) was used, so that only 19 valence electrons per atom were treated explicitly, together with the corresponding Gaussian basis set 2728 . The geometrical structures of $\mathrm{Ag}_{35}, \mathrm{Ag}_{55}, \mathrm{Ag}_{58}$ and $\mathrm{Ag}_{92}$ were taken from a study by Chen et al. ${ }^{29}$ using a genetic algorithm with an embedded atom method potential, while we took for $\mathrm{Ag}_{20}$ the ground state structure of $C_{S}$ symmetry obtained with DFT 8 . Of course we cannot be sure that these structures are indeed the lowest energy ones, but our tests show that the spectra characterized by a plasmon-like band are only weakly dependent on the exact geometrical cluster structure as long as the shape is somewhat spherical. The above structures were optimized within our calculations before setting off to determine their absorption spectra.

Calculations on clusters embedded in a neon matrix have been performed in two steps: first we optimized the structure of the cluster $\mathrm{Ag}_{n} \mathrm{Ne}_{100}$, in which the silver cluster is surrounded by 100 Ne atoms in an amorphous arrangement, and placed in a dielectric medium characterized by the dielectric function of solid neon $(\varepsilon=1.5)^{6}$. The structure optimisation was performed using the $\omega \mathrm{B} 97 \mathrm{xD}$ functional which includes empirical dispersion ${ }^{30}$. Then the absorption spectra were calculated with the hybrid functional within the solvent reaction field. All calculations were performed with the Gaussian09 suite of programs 31 .

\section{Results and discussion}

\subsection{Optical absorption spectra of $\mathbf{A g}_{1-120}$}

Figure 1] presents the measured absorption spectra in an energy range from 2 to $6 \mathrm{eV}$ for $\mathrm{Ag}_{n}$ ( $n=1,2,5,8,11,20,21,35,55,58,84,92,120)$ clusters embedded in solid neon at $6 \mathrm{~K}$. The spectra for $\mathrm{Ag}_{n}(n=1,2,5)$ are taken from ref. ${ }^{7}$ and are given here for completeness. The spectrum for $\mathrm{Ag}_{300}$ has been measured (non size selected) in a direct absorption measurement in the gas phase $\frac{40}{40}$. Spectra have been normalized to cluster density and to the number of atoms per cluster. The experimental data are shown in red. The blue lines are multi-gaussian fits with variable energy, intensity, and line-width. The respective positions and intensities are represented as vertical grey bars. We show in addition the calculated bulk limit, i.e., the optical spectrum in the dipolar approximation using the dielectric function of bulk silver ${ }^{32}$. This spectrum has been redshifted by $0.17 \mathrm{eV}$ in order to account for the dielectric shift of the Ne matrix ${ }^{33}$. Table 1 lists energy, intensity, and line-width for all fitted transitions. The central absorption energies of these clusters are around $4 \mathrm{eV}$, which is a typical plasmon energy for small silver clusters in the gas phase. Besides, we can see that $\mathrm{Ag}_{20}, \mathrm{Ag}_{55}$, and $\mathrm{Ag}_{92}$ show narrow absorption widths of around $0.3 \mathrm{eV}$ full width at half-maximum (FWHM), while the absorption profiles for $\mathrm{Ag}_{35}, \mathrm{Ag}_{58}, \mathrm{Ag}_{84}$, and $\mathrm{Ag}_{120}$ are with $0.5 \mathrm{eV}$ of FWHM significantly wider.

In order to compare to absorption spectra of clusters in the gas phase, the spectra of Fig. 1 have to be blue-shifted to remove the dielectric matrix shift. This shift was found to be $0.17 \mathrm{eV}$ for large cluster sizes down to $\mathrm{Ag}_{11} \frac{33}{3}$. To further scrutinize the validity of this blueshift, we compare in Fig. 22the TDDFT absorption spectra of $\mathrm{Ag}_{n}$ clusters in a Neon matrix, blue-shifted by $0.17 \mathrm{eV}$, with those obtained in the gas phase for $n=20,58,92$. The very good agreement between both calculations shows that the Ne matrix does not change the overall shape of the absorption features and that the value of $0.17 \mathrm{eV}$ is correct at least in the size range of $n=$ $20-92$. In our calculations, this shift is not validated for smaller particles, we rather find that the confinement compensates the dielectric effect for smaller particles such as $\mathrm{Ag}_{8}$. 


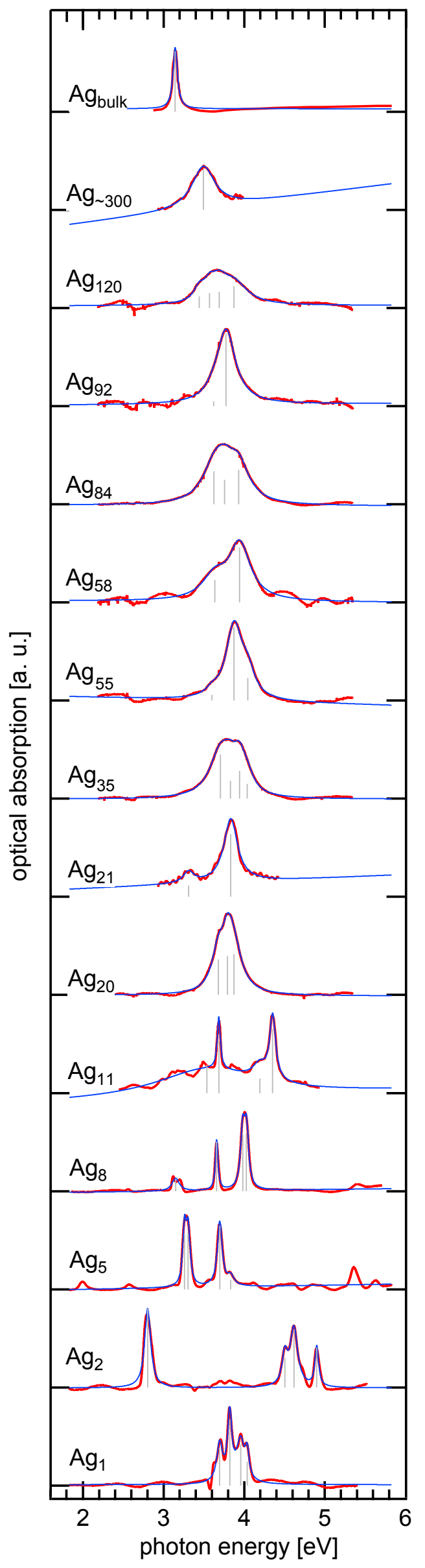

This journal is $\odot$ The Royal Society of Chemistry [year]

Fig. 1 Measured optical absorption spectra (red) of monodisperse $\mathrm{Ag}_{n}$ $(n=1-120)$ in Ne at $6 \mathrm{~K}$. Blue lines are multi-peak Gaussian fits, grey

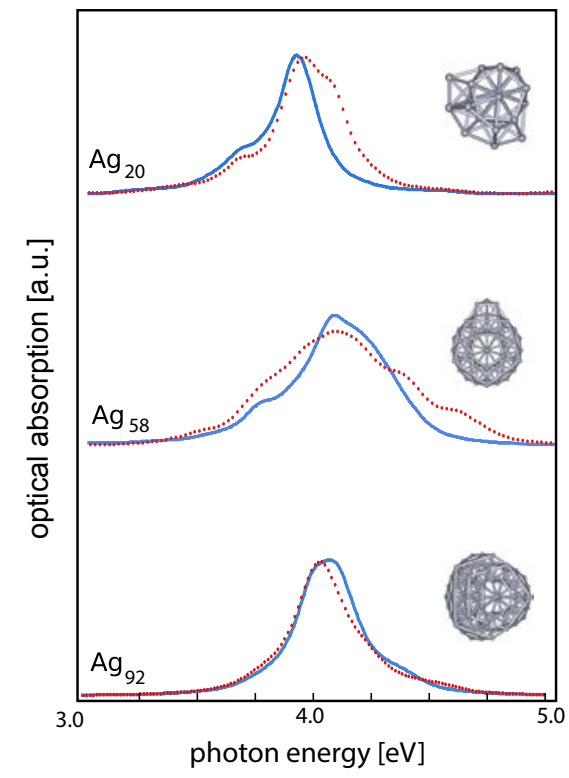

Fig. 2 Calculated absorption spectra of $\mathrm{Ag}_{n}$ clusters. Blue curve (-): TDDFT calculations for $\mathrm{Ag}_{n}$ in gas phase; dashed red curve ( $\left.\cdots\right)$ : TDDFT calculations for $\mathrm{Ag}_{n}$ in a neon matrix with a blueshift of $0.17 \mathrm{eV}$. Cluster structures are depicted for each size.

\subsection{Comparison with TDDFT calculations}

Figure 3 shows calculated spectra for the gas phase in comparison with experimental ones that were blue-shifted by $0.17 \mathrm{eV}$ to account for the matrix shift and represent the experimental gas phase spectra. Both, position and shape of the plasmon bands are very well reproduced for all four sizes. For $\mathrm{Ag}_{20}$, the simulated plasmon-like band is centered at $3.93 \mathrm{eV}$, compared to the blueshifted experimental value of $4.0 \mathrm{eV}$. It is composed of two transitions at 3.91 and $3.97 \mathrm{eV}$ respectively. For $\mathrm{Ag}_{35}$, a relative wide band, composed of two humps calculated at 3.95 and $4.12 \mathrm{eV}$, respectively, fits well the experimental spectrum. The first hump is due to two excitations at 3.91 and $3.96 \mathrm{eV}$ respectively, while the second one is due to several less intense transitions in the 4.11-4.18 eV range. For $\mathrm{Ag}_{55}$, the calculated plasmon band is centered at $4.13 \mathrm{eV}$, and slightly blueshifted with respect to the experimental band. The simulation reproduces the shoulder at $4.21 \mathrm{eV}$ very well, and predicts a small peak at $4.59 \mathrm{eV}$, not seen in experiments. Finally, the calculated spectrum of $\mathrm{Ag}_{58}$ shows a main transition at $4.08 \mathrm{eV}$ and a less intense one at $3.77 \mathrm{eV}$, in excellent agreement with the experimental data showing these features at 4.11 and $3.81 \mathrm{eV}$.

Concerning the cluster structure, previous calculations have found the highly symmetric tetrahedric $T_{d}$ structure for the corresponding sizes. While $\mathrm{Au}_{20}$ very likely has this structure, for $\mathrm{Ag}_{20}$ the lowest energy isomer is found to depend on the density functional and basis set used 29 . Aikens et al. have calculated the optical absorption spectra over a large set of cluster sizes with tetrahedra shell closings $(n=20,35,84,120) \underline{14}$. Comparison of these spectra with present experiment reveals important differ- 


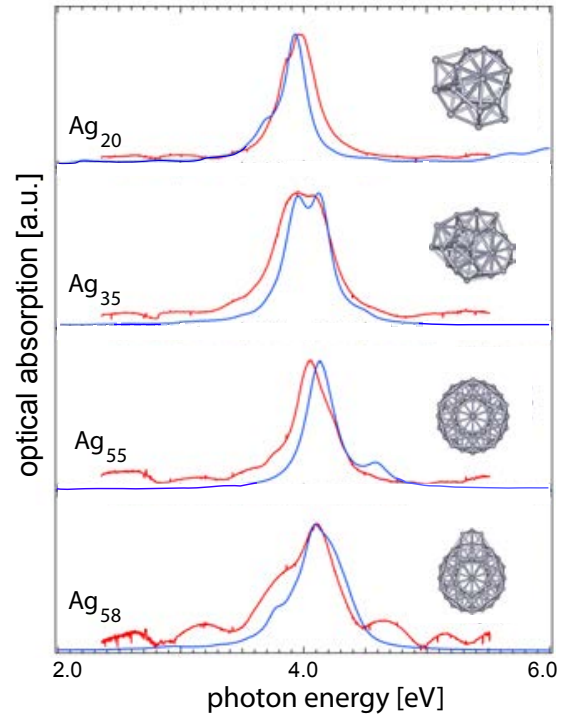

Fig. 3 Comparison of the experimental absorption spectra, blue-shifted by $0.17 \mathrm{eV}$ to remove the matrix shift (red curve -) and TDDFT calculations for clusters in the gas phase (blue curve -). Cluster structures are depicted for each size.

ences. For $\mathrm{Ag}_{20}$ the $T_{d}$ structure is characterized by one strong electronic transition at around $4 \mathrm{eV}$, while the experimental spectrum clearly is composed of multiple transitions (see Table 1) which together account for the total width of the absorption peak. It seems therefore plausible to assume a less symmetric structure, like the present calculated structure of $\mathrm{C}_{s}$ symmetry, as the lowest lying ground state for $\mathrm{Ag}_{20}$. Similarly, the $T_{d}$ symmetry for $\mathrm{Ag}_{35}$, $\mathrm{Ag}_{84}$ and $\mathrm{Ag}_{120}$ leads to rather narrow plasmon widths, while the experimental spectra of the corresponding sizes are broad compared to the ones of $\mathrm{Ag}_{55}$ and $\mathrm{Ag}_{92}$. An additional difference to the experimental data is the larger redshift of the plasmon peak with size of about $0.6 \mathrm{eV}$ in the calculations of $T_{d} \mathrm{Ag}_{n}$ clusters. Hence, this comparison with experiment clearly invalidates the assumption of $T_{d}$ structures, in agreement with electron diffraction measurements on charged clusters 34 . Very recently, Erhart et

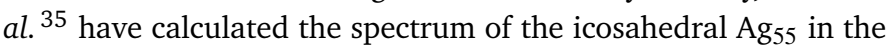
real-time TDDFT approach. Their main band centered at $\sim 4.2 \mathrm{eV}$ is in good agreement with our experimental result.

\subsection{Mean absorption energies and polarizabilities}

An interesting question is the size dependence of the surface plasmon energy which can be well defined by the single symmetric absorption peak for larger particles supposed to be spherical in shape. This situation is more complicated for smaller clusters whose shape deviates from the sphere with a splitting of the plasmon resonance in multiple peaks. A further complication arises from the perturbation of this resonance due to the dielectric influence of the substrate for supported clusters (inhomogenous dielectric environment) and embedded clusters (homogenous dielectric environment). Most experiments for larger clusters are, because of technical difficulties restricted to an ensemble of sizes which makes the attribution of an absorption profile to a specific size difficult. Exceptions are the recent electron energy loss measurements recorded with transmission electron microscopy on single Ag clusters supported on carbon grids from Scholl et al. $\frac{15}{15}$ and on silicon nitride by Raza et al. $\frac{38}{3}$. Figure 4 shows the plasmon energy against the inverse particle diameter $1 / D$. The data of Refs. 15 [37/39 have been shifted to obtain the resonance energies in vacuum. Please note, here we use $0.25 \mathrm{eV}$ instead of $0.29 \mathrm{eV} 16$ to blue shift the plasmon energy from argon matrix to vacuum according to the matrix effects ${ }^{33}$. Our present results for $\mathrm{Ag}_{n}$ in Ne matrices coincide perfectly with the older data for $\mathrm{Ag}_{n}$ in Ar. This shows again that matrix effects ${ }^{33}$ will only weakly influence the optical absorption of embedded clusters except for the red shift and justifies again the constant redshift of $0.17 \mathrm{eV}$ in Neon for all measured cluster sizes to extract gas phase energies.

Our results show a higher plasmon energy compared to Ref. 39 . We attribute this to the fact that the silver clusters used in that reference are not mass-selected. The larger clusters have larger signal than the smaller ones, so that averaging over a finite size distribution, and presenting this average as being caused by a single cluster, leads to systematic deviation to lower plasmon energies. This conclusion is consistent with the theoretical result of Ref. 41 .

Interestingly, we find that silver clusters with atom numbers of $8,18,34,58,92$ show a localised maximum value of the plasmon energy. According to the well-known shell model ${ }^{42}$, these numbers correspond to the fully filled states of $1 \mathrm{~S}, 1 \mathrm{P}, 1 \mathrm{D}, 1 \mathrm{~F}, 1 \mathrm{G}$ and $1 \mathrm{H}$. Our DFT calculations confirm such a filling. Indeed the electronic structure clearly shows the shell filling in which the $s$ valence electrons are found to be distributed in delocalized orbitals in the following energy sequence of electronic shell model $1 \mathrm{~S}^{2}, 1 \mathrm{P}^{6}, 1 \mathrm{D}^{10}, 2 \mathrm{~S}^{2}, 1 \mathrm{~F}^{14}, 2 \mathrm{P}^{6}, 1 \mathrm{G}^{18}, 2 \mathrm{D}^{10}, 3 \mathrm{~S}^{2}, 1 \mathrm{H}^{22}$, etc. As an illustration, the density of states (DOS) together with representative Kohn-Sham orbitals are given in Fig. 5 for $\mathrm{Ag}_{55}$. All molecular orbitals can be found in the supporting information, together with those of $\mathrm{Ag}_{20}$ and $\mathrm{Ag}_{92}$. For all clusters, we can easily distinguish the orbitals associated to S, P, D, F, G shells, even if some shells are splitting into subshells due to the lower symmetry with respect to the $\mathrm{K}_{h}$ group for a perfect sphere.

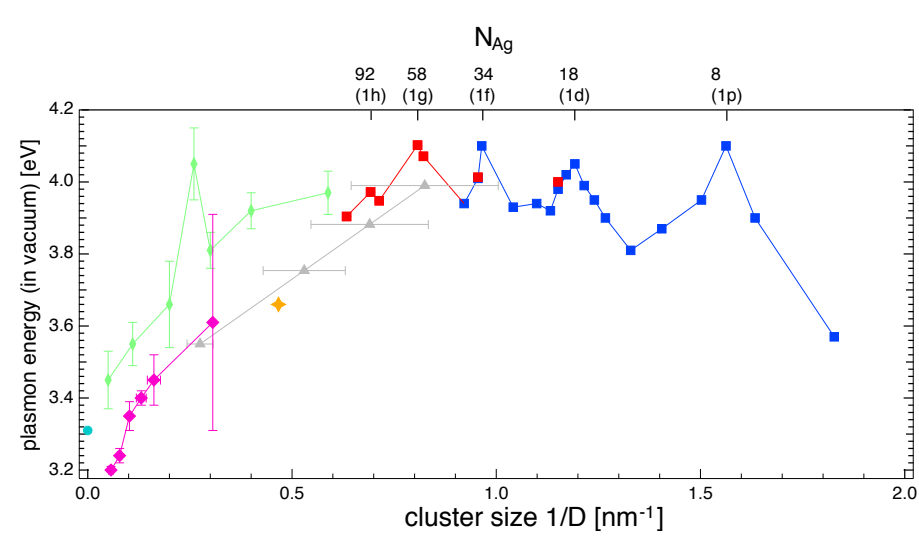

Fig. 4 Center of the surface plasmon resonance of silver particles in vacuum as a function of the inverse cluster diameter $1 / D$. 37 ; [39; 15 ; ; 38 ; 40.; 32; Present work; 


\begin{tabular}{|c|c|c|c|c|c|c|c|c|c|c|c|c|c|c|}
\hline \multirow{2}{*}{$\mathrm{Ag}_{n}$} & \multicolumn{2}{|c|}{ Plasmon } & \multicolumn{3}{|c|}{ Abs. peak 1} & \multicolumn{3}{|c|}{ Abs. peak 2} & \multicolumn{3}{|c|}{ Abs. peak 3} & \multicolumn{3}{|c|}{ Abs. peak 4} \\
\hline & $\begin{array}{l}\text { En. } \\
(\mathrm{eV})\end{array}$ & $\begin{array}{c}\text { FWHM } \\
(\mathrm{eV})\end{array}$ & $\begin{array}{l}\text { En. } \\
(\mathrm{eV})\end{array}$ & $\begin{array}{l}\text { Int. } \\
\text { (a.u.) }\end{array}$ & $\begin{array}{c}\text { FWHM } \\
(\mathrm{eV})\end{array}$ & $\begin{array}{l}\text { En. } \\
(\mathrm{eV})\end{array}$ & $\begin{array}{l}\text { Int. } \\
\text { (a.u.) }\end{array}$ & $\begin{array}{c}\text { FWHM } \\
(\mathrm{eV})\end{array}$ & $\begin{array}{l}\text { En. } \\
(\mathrm{eV})\end{array}$ & $\begin{array}{l}\text { Int. } \\
\text { (a.u.) }\end{array}$ & $\begin{array}{c}\text { FWHM } \\
(\mathrm{eV})\end{array}$ & $\begin{array}{l}\text { En. } \\
(\mathrm{eV})\end{array}$ & $\begin{array}{c}\text { Int. } \\
\text { (a.u.) }\end{array}$ & $\begin{array}{c}\text { FWHM } \\
(\mathrm{eV})\end{array}$ \\
\hline$\bullet 5$ & 3.4 & - & 3.26 & 2.86 & 0.05 & 3.3 & 2.86 & 0.06 & 3.70 & 3.29 & 0.07 & 3.83 & 0.49 & 0.10 \\
\hline$\bullet 8$ & 3.93 & - & 3.15 & 0.65 & 0.11 & 3.66 & 2.56 & 0.04 & 3.98 & 2.91 & 0.06 & 4.03 & 2.97 & 0.06 \\
\hline$* 11$ & 3.7 & - & 3.54 & 0.36 & 1.54 & 3.68 & 0.67 & 0.05 & 4.19 & 0.19 & 0.20 & 4.25 & 0.82 & 0.09 \\
\hline$\star 20$ & 3.83 & 0.316 & 3.68 & 1.10 & 0.19 & 3.79 & 1.20 & 0.17 & 3.87 & 1.26 & 0.24 & - & - & - \\
\hline$* 21$ & 3.75 & - & 3.31 & 0.14 & 0.16 & 3.83 & 0.81 & 0.21 & - & - & - & - & - & - \\
\hline$\star 35$ & 3.84 & 0.485 & 3.70 & 2.37 & 0.33 & 3.83 & 0.96 & 0.21 & 3.94 & 1.50 & 0.18 & 4.04 & 0.80 & 0.19 \\
\hline$\star 55$ & 3.9 & 0.320 & 3.60 & 0.12 & 0.17 & 3.87 & 1.56 & 0.25 & 4.04 & 0.48 & 0.20 & - & - & - \\
\hline$\star 58$ & 3.93 & 0.417 & 3.64 & 0.59 & 0.37 & 3.94 & 1.44 & 0.32 & - & - & - & - & - & - \\
\hline$\star 84$ & 3.77 & 0.504 & 3.62 & 2.32 & 0.34 & 3.76 & 1.73 & 0.28 & 3.93 & 2.43 & 0.31 & - & - & - \\
\hline$\star 92$ & 3.8 & 0.248 & 3.62 & 0.07 & 0.22 & 3.77 & 1.08 & 0.28 & - & - & - & - & - & - \\
\hline$\star 120$ & 3.73 & 0.530 & 3.44 & 0.20 & 0.16 & 3.57 & 0.25 & 0.18 & 3.69 & 0.28 & 0.23 & 3.87 & 0.37 & 0.42 \\
\hline$\diamond$ bulk & 3.14 & 0.07 & 3.14 & 0.63 & 0.07 & - & - & - & - & - & - & - & - & - \\
\hline
\end{tabular}

Table 1 Energies, intensities and widths of plasmons and transitions contributing to the absorption spectra. $\star$ this work; $\bullet 7$; $* 37$; $\diamond \sqrt{32}$.

The static polarizability of the clusters can be calculated from the experimental optical spectra as ${ }^{6}$ :

$$
\alpha=\frac{N e^{2}}{m_{e}} \cdot\left\langle\frac{1}{\omega^{2}}\right\rangle=\frac{N e^{2}}{\varepsilon_{0} m_{e}} \cdot \frac{\int_{0}^{\infty} \frac{1}{\omega^{2}} \cdot \sigma(\omega) \mathrm{d} \omega}{\int_{0}^{\infty} \sigma(\omega) \mathrm{d} \omega} .
$$

where $N$ is the total number of electrons in the cluster, $\omega$ the absorption energy, and $\sigma$ the absorption cross section. The polarizability divided by the number of atoms is shown in Fig. 6, together with data for smaller clusters from earlier measurements 17 18. We find values from 0.7 - 1.0. Local minima are observed for the shell closings, corresponding to the stiffest clusters. An exception makes $\mathrm{Ag}_{55}$ which is the geometrical shell closing of the icosahedron ( $I_{h}$ group) rather than 58 which is the filling of the $1 \mathrm{G}$ state. Static polarizabilities can also be extracted from the DFT calculations. We show in Fig. 6 the DFT values calculated at $\omega \mathrm{B} 97 \mathrm{x} / \mathrm{def} 2 \mathrm{TZVP}{ }^{43}$ level using the geometrical structures proposed by Chen et al.29. To obtain values per atom as in experiment we calculate $\alpha(\mathrm{Ag})$ per atomic volume of $7.45 \AA^{3}$. They show good agreement with experiment, even if the calculated

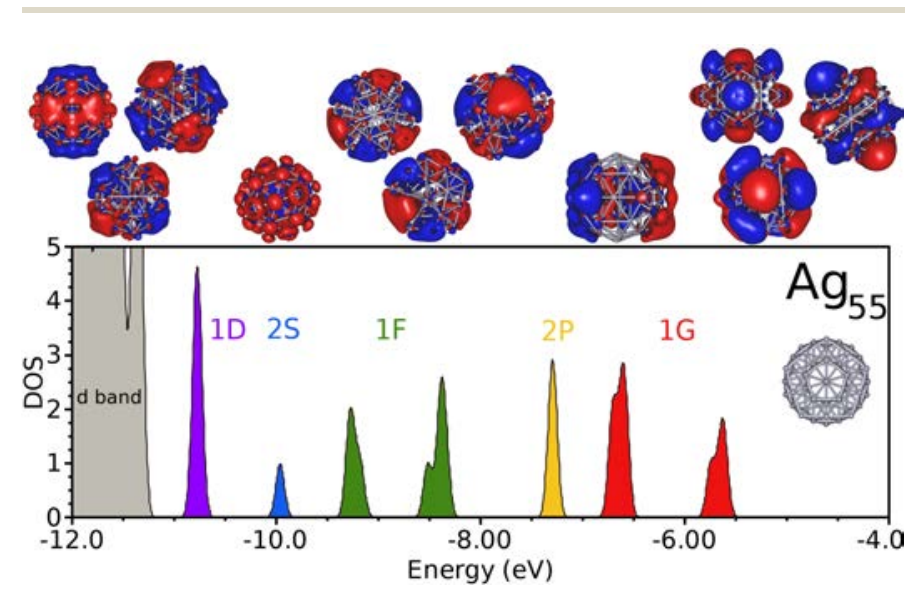

Fig. 5 Density of states of $\mathrm{Ag}_{55}^{+}$together with the representative KohnSham molecular orbitals aligned above the DOS peaks. Blue and red refer to positive and negative sign of the molecular orbitals. More molecular orbitals (together with those of $\mathrm{Ag}_{20}$ and $\mathrm{Ag}_{92}$ ) are given in the supporting information. values for small cluster sizes are slightly above the experimental ones. The minima at $n=8,18,34,55$, and 92 are well reproduced. It is worth noticing that the experimental values obtained with the formula (1) integrated up to $5 \mathrm{eV}$ are in good agreement with the exact calculated values because the static polarizability results mainly from valence electrons.

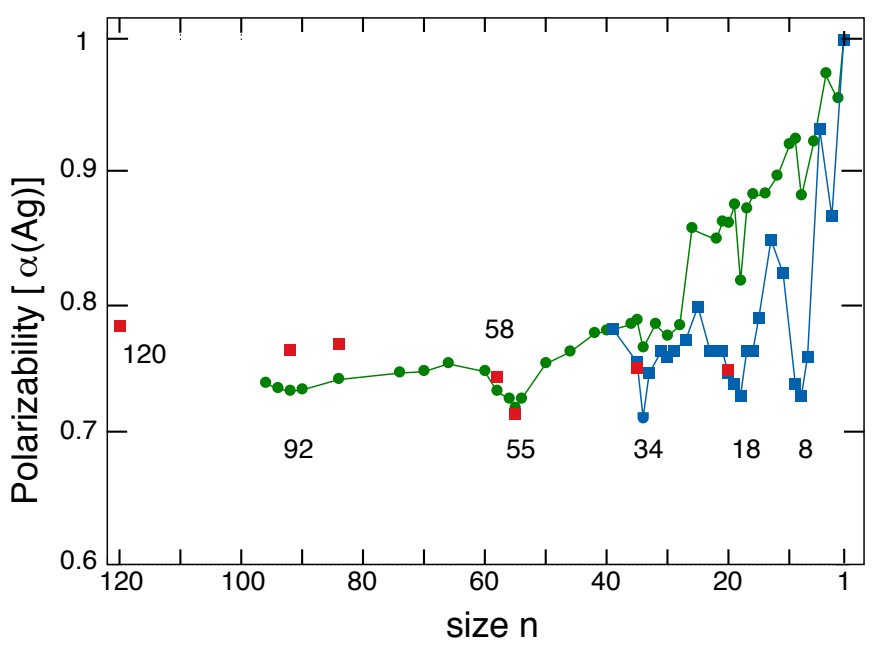

Fig. 6 Experimental and theoretical results of the polarizability of silver clusters as a function of the cluster size. $\mathrm{Ag}_{n}$ embedded in argon 18; $\mathrm{Ag}_{n}$ embedded in neon (present work); • DFT (present work).

Our data manifest that the clusters with fully filled states have higher plasmon energies and lower static polarizabilies than clusters with partial filled states. A similar finding has been reported by Puska et al. 44 in DFT calculations for simple metal clusters (Li, $\mathrm{Al})$. Relating the optical resonance $\omega_{1}$ to the static polarizability through the equation 6 :

$$
\omega_{1}=\sqrt{\frac{N e^{2}}{m_{e} \alpha}} .
$$

allows us to conclude that the higher plasmon energies for magic 
numbers reflect small polarizabilities.

\section{Conclusions}

We present optical absorption spectra of mass selected $\mathrm{Ag}_{n}$ ( $n=$ $5,20,35,55,58,84,92,120)$ clusters embedded in a solid neon matrix. This extends the size range to fill the gap in the center position of plasmon resonances of neutral silver clusters. All spectra, although showing a plasmon like absorption profile, are composed of multiple transitions. TDDFT calculations are in excellent agreement with the experimental spectra. The plasmon energies lie between $3.9-4.1 \mathrm{eV}$ with an absorption width (FWHM) between $0.3-0.5 \mathrm{eV}$ depending on the shape of the cluster. Plasmon energies and static polarizabilities are structured and clearly show shell effects where the silver clusters with atom numbers fully filling the states with the lowest quantum level of $v=1$ show a localized maximum value of the plasmon energy.

\section{Conflicts of interest}

There are no conflicts to declare'.

\section{Acknowledgements}

We acknowledge support from the Swiss National Science Foundation (Grant 200020_149388). RS and FR thank the GENCIIDRIS (Grant i2015086864) center for generous allocation of computational time.

\section{Notes and references}

1 M. C. Daniel and D. Astruc, Chem. Rev., 2004, 104, 293.

2 T. W. Odom and G. C. Schatz, Chem. Rev., 2011, 111, 3667.

3 H. Chen, M. G. Blaber, S. D. Standridge, E. J. DeMarco, J. T. Hupp, M. A. Ratner and G. C. Schatz, J. Phys. Chem. C, 2012, 116, 10215.

4 U. Heiz and U. Landman, Nanocatalysis, Springer, Berlin, 2007.

5 V. Bonacic-Koutecky and T. M. Bernhardt, Phys. Chem. Chem. Phys., 2012, 14, 9252.

6 U. Kreibig and M. Vollmer, Optical Properties of Metal Clusters, Springer, Berlin, 1995, vol. 25.

7 S. Lecoultre, A. Rydlo, J. Buttet, C. Félix, S. Gilb and W. Harbich, J. Chem. Phys., 2011, 134, 184504.

8 M. Harb, F. Rabilloud, D. Simon, A. Rydlo, S. Lecoultre, F. Conus, V. Rodrigues and C. Félix, J. Chem. Phys., 2008, 129, 194108.

9 F. Rabilloud, J. Chem. Phys., 2014, 141, 144302.

10 B. Anak, M. Bencharif and F. Rabilloud, Rsc Advances, 2014, 4, 13001.

11 F. Xuan and C. Guet, Phys. Rev. A, 2017, 96, 043404.

12 M. Moseler, H. Hakkinen and U. Landman, Phys. Rev. Lett., 2001, 87, 053401.

13 U. Landman, PNAS, 2005, 102, 6671.

14 C. M. Aikens, S. Li and G. C. Schatz, J. Phys. Chem., 2008, 112, 11272.

15 J. A. Scholl, A. L. Koh and J. A. Dionne, Nature, 2012, 483, 421.
16 H. Haberland, Nature, 2013, 494, E1.

17 S. Fedrigo, W. Harbich and J. Buttet, Phys. Rev. B, 1993, 47, 10706.

18 S. Fedrigo, W. Harbich, J. Belyaev and J. Buttet, Chem. Phys. Lett., 1993, 211, 166.

19 I. M. Goldby, B. v. Issendorff, L. Kuipers and R. E. Palmer, Rev. Sci. Instrum., 1997, 68, 3327.

20 C. Yu, W. Harbich, L. Sementa, L. Ghiringhelli, E. Apra, M. Stener, A. Fortunelli and H. Brune, J. Phys. Chem., 2017, $147,074301$.

21 M. Rottgen, K. Judai, J. M. Antonietti, U. Heiz, S. Rauschenbach and K. Kern, Rev. Sci. Instrum., 2006, 77, 13302.

22 L. Jensen, L. Zhao and G. C. Schatz, J. Phys. Chem. C, 2007, 111, 4756.

23 N. Thakkar, N. P. Montoni, C. Cherqui and D. J. Masiello, Phys. Rev. B, 2018, 97, 121403.

24 J. D. Chai and M. Head-Gordon, J. Chem. Phys., 2008, 128, 084106.

25 Y. Zhao and D. G. Truhlar, J. Chem. Phys., 2006, 125, 194101.

26 H. Iikura, T. Tsuneda, T. Yanai and K. Hirao, J. Chem. Phys., 2001, 115, 3540.

27 P. J. Hay and W. R. Wadt, J. Chem. Phys., 1985, 82, 299.

28 D. Andrae, U. Haussermann, M. Dolg, H. Stoll and H. Preuss, Theor. Chem. Acc., 1990, 77, 123.

29 M. Chen, J. E. Dyer, K. Li and D. A. Dixon, J. Phys. Chem. A, 2013, 117, 8298.

30 J. D. Chai and M. Head-Gordon, Phys. Chem. Chem. Phys., 2008, 10, 6615.

31 M. J. Frisch, G. W. Trucks, H. B. Schlegel, G. E. Scuseria, M. A. Robb, J. R. Cheeseman, G. Scalmani, V. Barone, B. Mennucci, G. A. Petersson, H. Nakatsuji, M. Caricato, X. Li, H. P. Hratchian, A. F. Izmaylov, J. Bloino, G. Zheng, J. L. Sonnenberg, M. Hada, M. Ehara, K. Toyota, R. Fukuda, J. Hasegawa, M. Ishida, T. Nakajima, Y. Honda, O. Kitao, H. Nakai, T. Vreven, J. A. M. Jr., J. E. Peralta, F. Ogliaro, M. Bearpark, J. J. Heyd, E. Brothers, K. N. Kudin, V. N. Staroverov, R. Kobayashi, J. Normand, K. Raghavachari, A. Rendell, J. C. Burant, S. S. Iyengar, J. Tomasi, M. Cossi, N. Rega, J. M. Millam, M. Klene, J. E. Knox, J. B. Cross, V. Bakken, C. Adamo, J. Jaramillo, R. Gomperts, R. E. Stratmann, O. Yazyev, A. J. Austin, R. Cammi, C. Pomelli, J. W. Ochterski, R. L. Martin, K. Morokuma, V. G. Zakrzewski, G. A. Voth, P. Salvador, J. J. Dannenberg, S. Dapprich, A. D. Daniels, A. Farkas, J. B. Foresman, J. V. Ortiz, J. Cioslowski and D. J. Fox, Gaussian 09 Revision D.01, Gaussian Inc. Wallingford CT, 2009.

32 P. B. Johnson and R. W. Christy, Phys. Rev. B, 1972, 6, 4370.

33 S. Fedrigo, W. Harbich and J. Buttet, Int. J. Mod. Phys. B, 1992, 6, 23.

34 D. Schooss, M. N. Blom, J. H. Parks, B. v. Issendorff, H. Haberland and M. M. Kappes, Nanolett., 2005, 5, 1972.

35 T. P. Rossi, M. Kuisma, M. J. Puska, R. M. Nieminen and P. Erhart, J. Chem. Theory Comp., 2017, 13, 4779.

36 O. Baseggio, M. D. Vetta, G. Fronzoni, M. Stener, L. Sementa, 
A. Fortunelli and A. Calzolari, J. Phys. Chem. C, 2016, 120, 12773.

37 W. Harbich, S. Fedrigo and J. Buttet, Z. Phys. D, 1993, 26, 138.

38 S. Raza, W. Yan, N. Stenger, M. Wubs and N. A. Mortensen, Opt. Exp., 2013, 21, 27344.

39 K. P. Charle, L. König, S. Nepijko, I. Rabin and W. Schulze, Cryst. Res. Technol., 1998, 33, 7.
40 H. Hövel, S. Fritz, A. Hilger, U. Kreibig and M. Vollmer, Phys. Rev. B, 1993, 48, 18178.

41 V. Kasperovich and V. V. Kresin, Phil. Mag. B, 1998, 78, 385.

42 W. A. d. Heer, Rev. Mod. Phys., 1993, 65, 611.

43 F. Weigend and R. Ahlrichs, Phys. Chem. Chem. Phys., 2005, 7, 3297.

44 M. J. Puska, R. M. Nieminen and M. Manninen, Phys. Rev. B, 1985, 31, 3486. 


\section{Supporting Information}

\section{Optical properties of size selected neutral Ag clusters: electronic shell stuctures and the surface plasmon resonance}

Chongqi Yu, ${ }^{* a}$ Romain Schira, ${ }^{b \ddagger}$ Harald Brune, ${ }^{a \ddagger}$ Bernd von Issendorff, ${ }^{c \dagger}$ Franck Rabilloud, ${ }^{b \ddagger}$ and Wolfgang Harbich ${ }^{a}$

${ }^{a}$ Institute of Physics, Ecole Polytechnique Fédérale de Lausanne (EPFL), CH-1015 Lausanne, Switzerland

${ }^{b}$ Université Claude Bernard Lyon 1, CNRS, Institut Lumière Matière, F-69622 Villeurbanne, France

${ }^{c}$ Université Fakultät für Physik, Universität Freiburg, Germany

DFT calculations have been performed using the exchange and correlation functional $\omega \mathrm{B} 97 \mathrm{x}^{1}$ and a relativistic effective core potential (RECP), so that only 19 electrons per atom were treated explicitly, together with the corresponding Gaussian basis set ${ }^{213}$. The geometrical structures of $\mathrm{Ag}_{n}$ have been taken from a study by Chen et al. ${ }^{4}$ using a genetic algorithm with an embedded atom method potential, except that of $\mathrm{Ag}_{20}$ which has been taken as the ground state structure of $C_{s}$ symmetry obtained with $\mathrm{DFT}^{5}$. Calculations have been performed with the Gaussian09 suite of programs ${ }^{6}$.

The three figures S1, S2, S3 give the density of states (DOS) together with the Kohn-Sham orbitals of valence orbitals for $\mathrm{Ag}_{20}, \mathrm{Ag}_{55}$ and $\mathrm{Ag}_{92}$. The s-type valence electrons are found to be distributed in the following energy sequence of electronic shell model $1 \mathrm{~S}^{2}, 1 \mathrm{P}^{6}, 1 \mathrm{D}^{10}, 2 \mathrm{~S}^{2}, 1 \mathrm{~F}^{14}, 2 \mathrm{P}^{6}, 1 \mathrm{G}^{18}, 2 \mathrm{D}^{10}, 3 \mathrm{~S}^{2}, 1 \mathrm{H}^{22}$. We can easily distinguish the orbitals associated to S, P, D, F, G supershells. Some shells are splitting into subshells due to the lower symmetry with respect to the $\mathrm{K}_{h}$ group for a perfect sphere, and the atomic structure.
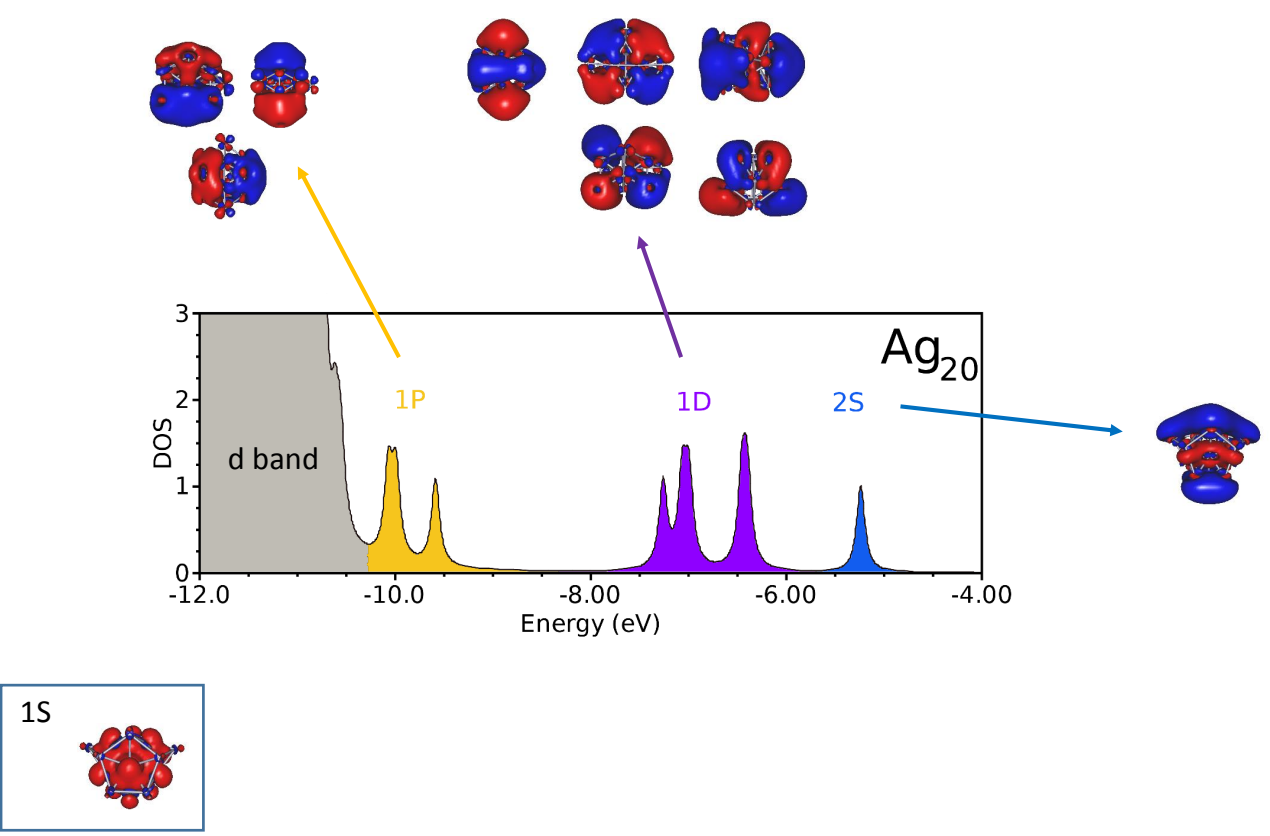

Figure S1: Density of states of $\mathrm{Ag}_{20}$ together with the representative Kohn-Sham molecular orbitals. Blue and red refer to positive and negative sign of the molecular orbitals. The orbital 1S is located inside the $\mathrm{d}$ band. 


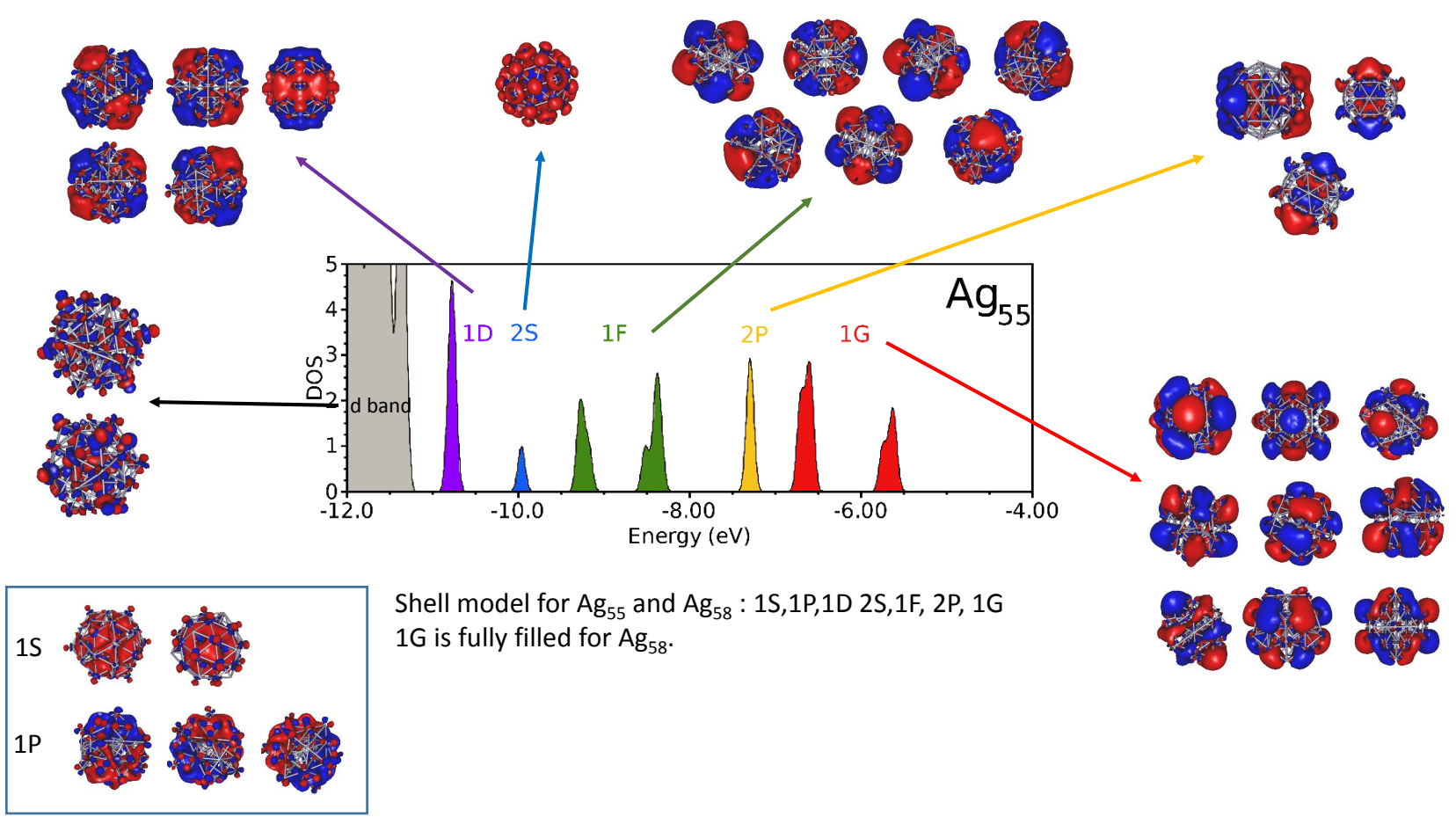

Figure S2: Density of states of $\mathrm{Ag}_{55}$ together with the representative Kohn-Sham molecular orbitals. Blue and red refer to positive and negative sign of the molecular orbitals. The orbitals $1 \mathrm{~S}$ and $1 \mathrm{P}$ are located inside the $\mathrm{d}$ band.

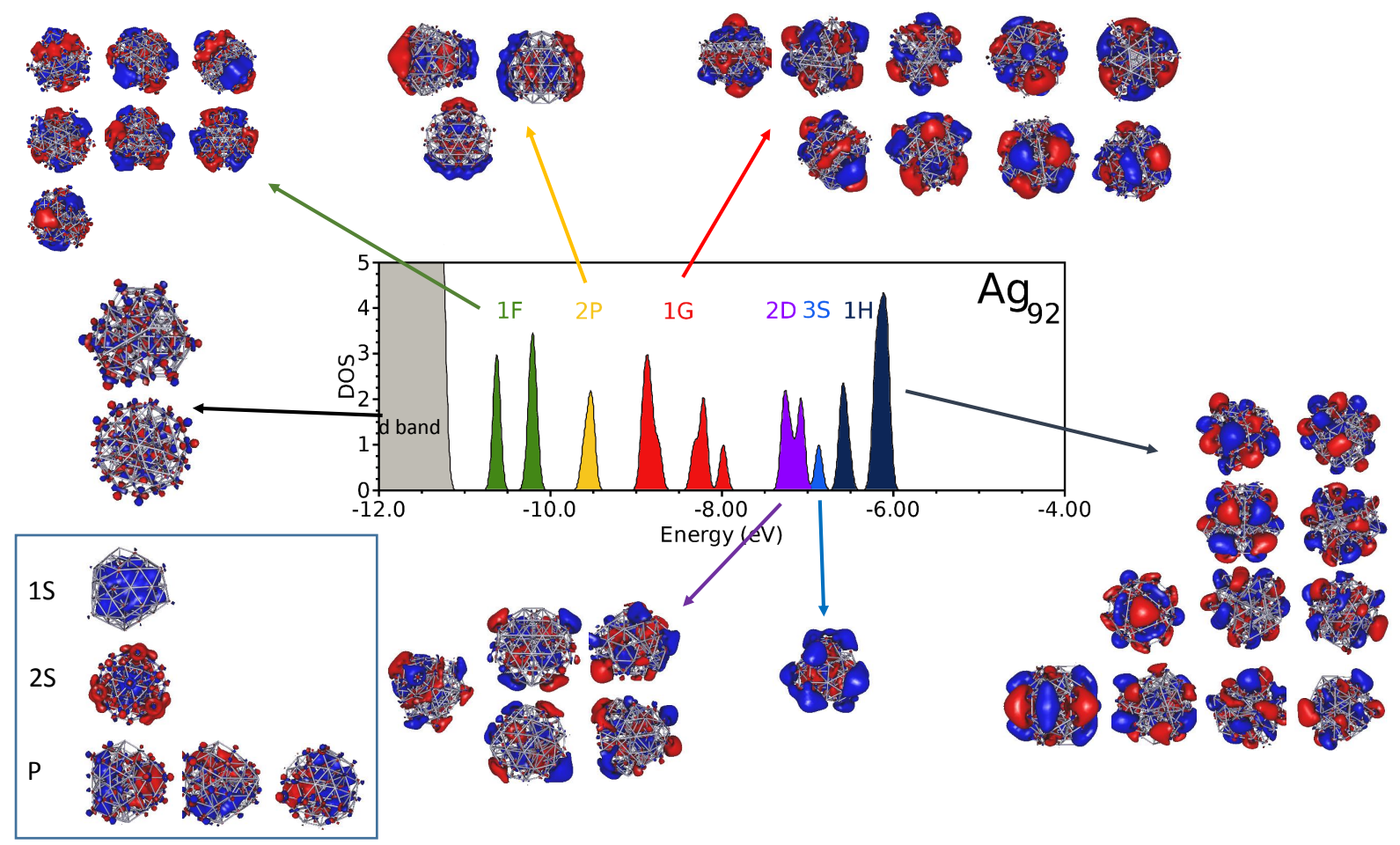

Figure S3: Density of states of $\mathrm{Ag}_{92}$ together with the representative Kohn-Sham molecular orbitals. Blue and red refer to positive and negative sign of the molecular orbitals. The orbitals $1 \mathrm{~S}, 1 \mathrm{P}, 1 \mathrm{D}$, and $2 \mathrm{~S}$ are located inside the d band. 


\section{Notes and references}

1 J. D. Chai and M. Head-Gordon, J. Chem. Phys., 2008, 128, 084106.

2 P. J. Hay and W. R. Wadt, J. Chem. Phys., 1985, 82, 299.

3 D. Andrae, U. Haussermann, M. Dolg, H. Stoll and H. Preuss, Theor. Chem. Acc., 1990, 77, 123.

4 M. Chen, J. E. Dyer, K. Li and D. A. Dixon, J. Phys. Chem. A, 2013, 117, 8298.

5 M. Harb, F. Rabilloud, D. Simon, A. Rydlo, S. Lecoultre, F. Conus, V. Rodrigues and C. Félix, J. Chem. Phys., 2008, 129, 194108.

6 M. J. Frisch, G. W. Trucks, H. B. Schlegel, G. E. Scuseria, M. A. Robb, J. R. Cheeseman, G. Scalmani, V. Barone, B. Mennucci, G. A. Petersson, H. Nakatsuji, M. Caricato, X. Li, H. P. Hratchian, A. F. Izmaylov, J. Bloino, G. Zheng, J. L. Sonnenberg, M. Hada, M. Ehara, K. Toyota, R. Fukuda, J. Hasegawa, M. Ishida, T. Nakajima, Y. Honda, O. Kitao, H. Nakai, T. Vreven, J. A. M. Jr., J. E. Peralta, F. Ogliaro, M. Bearpark, J. J. Heyd, E. Brothers, K. N. Kudin, V. N. Staroverov, R. Kobayashi, J. Normand, K. Raghavachari, A. Rendell, J. C. Burant, S. S. Iyengar, J. Tomasi, M. Cossi, N. Rega, J. M. Millam, M. Klene, J. E. Knox, J. B. Cross, V. Bakken, C. Adamo, J. Jaramillo, R. Gomperts, R. E. Stratmann, O. Yazyev, A. J. Austin, R. Cammi, C. Pomelli, J. W. Ochterski, R. L. Martin, K. Morokuma, V. G. Zakrzewski, G. A. Voth, P. Salvador, J. J. Dannenberg, S. Dapprich, A. D. Daniels, A. Farkas, J. B. Foresman, J. V. Ortiz, J. Cioslowski and D. J. Fox, Gaussian 09 Revision D.01, Gaussian Inc. Wallingford CT, 2009. 